\title{
Subperiosteal resection of mid-clavicle in Sprengel's deformity correction
}

\author{
Freih Odeh Abuhassan
}

Received: 10 February 2011/ Accepted: 9 July 2011/Published online: 20 July 2011

(C) The Author(s) 2011. This article is published with open access at Springerlink.com

\begin{abstract}
We report the results of fifteen cases of Sprengel's deformity treated surgically by initial subperiosteal resection of the middle third of the clavicle in conjunction with surgical release of all attachments of the scapula to the spine, excision of any omovertebral bone and resection of prominent supraspinous process of scapula. The patients included ten female and three male patients (age range at the time of operation, 3.3-10 years; mean: 6.11 years). The deformity involved the left shoulder in eight patients, the right shoulder in three and two were bilateral. All patients were followed for an average of 5.9 years (range 4-11 years). Preoperatively, the arc of total abduction (glenohumeral and scapulothoracic) ranged from 80 to $140^{\circ}$, and the average was $110^{\circ}$. The shoulders were level, and the range of motion was dramatically improved with an average range of abduction of $166.5^{\circ}$ (range $140-180^{\circ}$ ). The age of the patients and the presence of an omovertebral bone did not influence the results. All patients and their parents expressed satisfaction with the operative results. We feel that our procedure is a simple one, which helps to improve the degree of correction, avoid neurovascular complications and has the advantage of complete regeneration of the clavicle. The technique provides an easy, safe method of repositioning the scapula at its normal level.
\end{abstract}

Keywords Clavicle $\cdot$ Shoulder $\cdot$ Deformity $\cdot$ Sprengel's

F. O. Abuhassan $(\bowtie)$

The Department of Orthopaedic Surgery, The University of Jordan, Queen Rania street, PO Box: 73, Jubaiha, Amman 11941, Jordan

e-mail: freih@ju.edu.jo

\section{Introduction}

Sprengel's deformity is a complex structural abnormality of the shoulder girdle associated with malpositioned dysplastic scapula with muscle hypoplasia or atrophy; this causes disfigurement and limitation of shoulder movement. The aetiology of Sprengel's deformity is related to limb bud formation, which results in disruption of normal sequence of development during the foetal period $[1,2]$. It is often accompanied by other congenital anomalies [3, 4].

The cosmetic deformity and limitation of abduction remain the major concern and are sometimes accompanied by functional impairment. Congenital elevation of the scapula in Sprengel's deformity remains a complex therapeutic problem [5]. Surgical treatment is recommended in significantly involved patients to improve the cosmetic appearance and function of the involved shoulder. Many surgical procedures have been described with varying results [6-10]. We present a technique that not only produces a safe repositioning of the scapula but also improves the function of the shoulder girdle.

\section{Patients and methods}

Between 1999 and 2006, fifteen cases of Sprengel's deformity in thirteen patients were treated by our technique. There were ten girls and three boys. The average age at the time of surgery was 6.11 years (range 3.3-10 years). The deformity involved the left shoulder in eight patients, the right shoulder in three and two were bilateral. The preoperative screening protocol included a thorough physical examination and radiological assessment of the chest and cervical and thoracic spine. 
All cases of Cavendish grade IV (Table 1) had CT scan and $3 \mathrm{D}$ reconstruction of the shoulder and the scapula to exclude associated omovertebral connection (Fig. 1). The investigations represented an attempt to identify any associated anomalies that might accompany the Sprengel's deformity, including scoliosis, anomalies of rib or vertebral segments, omovertebral bone connection, torticollis, and musculo hypoplasia, especially around the shoulder. All cases of associated congenital scoliosis had magnetic resonance imaging (MRI) to exclude underlying associated spinal cord anomalies. Twelve of the thirteen patients had an associated congenital anomaly. Seven of these twelve patients had more than one associated abnormality. The most common abnormalities were congenital scoliosis in six patients, omovertebral bar in six patients, absent or fused ribs in three patients, and Klippel-Feil deformities in two patients (Table 2).

The other significant abnormalities included Syringomyelia (two patients) and diastematomyelia (one patient). Although accurate measurement of scapular lowering is difficult due to the hypoplastic nature of the affected scapula, we did use standing anterior posterior radiographs of both scapulae and chest to measure scapular lowering and were compared with the preoperative radiographs. The distance of elevation of the scapula was measured using the method described by Carson et al. [11]. The method entails measurement of the distance between the inferior scapular corners of each side. For bilateral deformities, each point was measured against a bony landmark on the spine.
We draw a parallel transverse lines passing through the inferior scapular corners and measure the distance difference between the inferior scapular corner of the abnormal side preoperative and postoperative. Preoperatively, the severity of the deformity was assessed on the basis of the four-grade system established by Cavendish (Table 1) [12]. The gender, age of patients at operation, preoperative and postoperative Cavendish classification grades, preoperative and postoperative shoulder abduction angles, and followup period were recorded (Table 3). All patients had photographic documentation of their shoulder function before and after surgery, deformity improvement shown by the position of shoulder joints and the appearance of postoperative scars (Fig. 2).

\section{Surgical technique}

All patients had the same surgical approach from the author. The operation was performed with the patient under general anaesthesia in a supine then in a prone position. Initially, while the patient was in a supine position with a sandbag between the scapular blades and facing the opposite side, the area of operation was prepared and draped followed by a $3-\mathrm{cm}$ supraclavicular incision made $2 \mathrm{~cm}$ cephalad to the mid-portion of the clavicle, in line with the skin creases.

The deep fascia was incised, and the periosteum of the clavicle divided longitudinally. The underlying subclavian vessels and brachial plexus were carefully protected by fine

Table 1 Cavendish grading

\begin{tabular}{llll}
\hline Grade & Severity & Shoulder level & Deformity \\
\hline I & Very mild & Shoulder joints are level & Invisible when the patient is dressed \\
II & Mild & Shoulder joints are level & Obvious when the patient is dressed \\
III & Moderate & The affected shoulder is elevated $2-5 \mathrm{~cm}$ & Obvious lump in the web of the neck \\
IV & Severe & The affected shoulder is elevated $>5 \mathrm{~cm}$ & Superior angle of the scapula is near the occiput \\
\hline
\end{tabular}

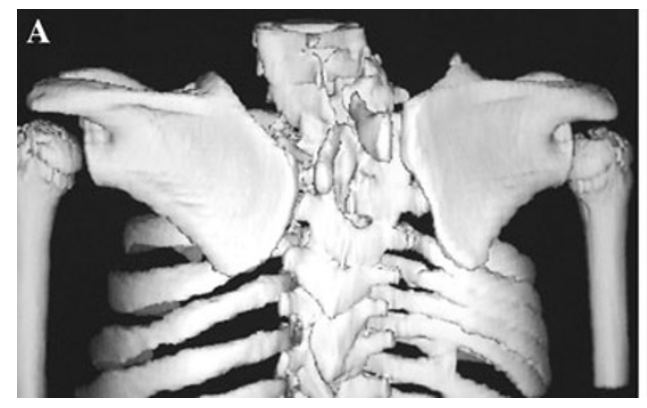

Fig. 1 A 7-year-old female child had multiple congenital anomalies. a and b 3D computerized axial tomography scan (CAT Scan) of the both scapulae (posterior view and top view), showing bilateral

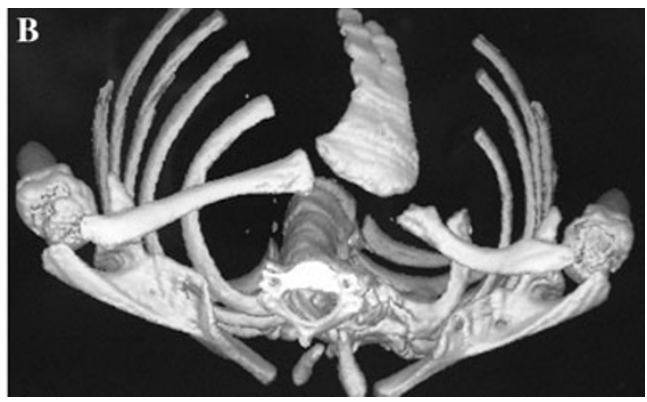

Sprengel's deformity with bilateral omovertebral bony connections, congenital scoliosis, and fused ribs on the right side (Case no. 7 Table 2) 
Table 2 Associated congenital anomalies in 13 patients

\begin{tabular}{lll}
\hline Associated abnormalities & Number of patients & $\%$ \\
\hline Congenital scoliosis & 6 & 46.15 \\
Omovertebral bone & 6 & 46.15 \\
Absent or fused ribs & 3 & 23 \\
Klippel-Feil deformities & 2 & 15.38 \\
Syringomyelia & 2 & 15.38 \\
Diastematomyelia & 1 & 7.7 \\
\hline
\end{tabular}

bone levers inserted inside the periosteal sheath. With a bone cutter, one inch of the middle third of the clavicle was taken out, followed by continuous closure of the periosteal sheath using 4/0 Vicryl forming periosteal tube and subcuticular suture for the skin (Figs. 3 and 4). Next, the patient was turned to the prone position, and the area of operation was prepared and draped with the ipsilateral upper extremity included in the operative field.

A mid-line longitudinal incision was made from the mid-cervical spine to the ninth thoracic spine. Dissection of the subcutaneous tissue up to the lateral border of the scapula releases all the trapezius muscle attachments laterally from the spine of the scapula and reflected medially (Fig. 5). Care was taken to avoid injury to the spinal accessory nerve. The supraspinatus muscle was then detached extraperiosteally to the greater scapular notch. The transverse scapular artery and the suprascapular neurovascular bundle were protected. The omovertebral bar was then excised, starting with scapular attachment. The omovertebral bar was gently detached from its insertion to the cervical spine. The insertions of the levator scapulae and rhomboid muscles were extraperiosteally dissected, divided from the medial scapular border, and tagged
(Fig. 6). Resection of the prominent superiomedial portion and the supraspinous portion was performed, followed by diathermy of the bone edges to avoid new bone formation. The scapular attachments of the latissimus dorsi muscle were divided extraperiosteally. Blunt dissection was used to create a large pocket in the superior part of the latissimus dorsi muscle.

Fibrous bands may connect the scapula to the chest wall; these should be divided by blunt dissection using gause and finger in order to mobilise the scapula. We do ask the anaesthetist to abduct both shoulders to around $120^{\circ}$; then, we do apply gentle downward pressure on the upper part of the scapula by index and middle finger to allow the scapula to be descend distally to the desired possible position without tension.

The desired rib, or the rib above according to the descent and size of the scapula, compared with the level of the normal side, which is usually the seventh rib posteriorly. The rib is opened subperiosteally all around, and small blunt bone levers are used to protect the underlying tissue (Fig. 7). Using a towel clip, a hole is opened in the rib, and the lower pole of the scapula is sutured to the rib and fixed by size 2.0 vicryl suture (Fig. 8). The muscles were reattached in the following order: supraspinatus muscle to the base of the scapular spine, subscapularis muscle to the vertebral border of the scapula, serratus anterior muscle to the vertebral border, the length end levator scapulae muscle then sutured to the superior border, rhomboid muscles reattached at a higher site to the medial border of the scapula and the superior border of the latissimus dorsi muscle to the posterior scapular muscle above the inferior angle of the scapula (Fig. 9).

Finally, the levator scapulae muscle reattached to the spine of the scapula. Redivac drain size 14.0 was inserted

Table 3 Demographic and clinical data of treated patients with subperiosteal resection of the clavicle for Sprengel deformity

\begin{tabular}{|c|c|c|c|c|c|c|c|}
\hline No & Sex & $\begin{array}{l}\text { Age } \\
\text { years }+ \text { months }\end{array}$ & $\begin{array}{l}\text { Preop. Cavendish } \\
\text { classification }\end{array}$ & $\begin{array}{l}\text { Postop. Cavendish } \\
\text { classification }\end{array}$ & $\begin{array}{l}\text { Preoperative } \\
\text { abduction }\end{array}$ & $\begin{array}{l}\text { Postoperative } \\
\text { abduction }\end{array}$ & $\begin{array}{l}\text { Follow-up/ } \\
\text { year }\end{array}$ \\
\hline 1 & Female & 10 years & IV & II & 90 & 150 & 5 \\
\hline 2 & Female & 5 years +4 months & IV & I & 110 & 170 & 6 \\
\hline 3 & Female & 3 years +5 months & III & I & 120 & 180 & 5.5 \\
\hline 4 & Female & 4 years & IV & I & 100 & 170 & 5 \\
\hline 5 & Male & 6 years & III & I & 130 & 165 & 6 \\
\hline 6 & Male & 4 years +8 months & III & I & 130 & 170 & 5 \\
\hline 7 & Female & 7 years & IV & I & 90 & 160 & 5 \\
\hline 8 & Male & 8 years +5 months & IV & II & 110 & 180 & 7 \\
\hline 9 & Female & 4 years +5 months & IV & I & 100 & 170 & 7.5 \\
\hline 10 & Female & 6 years & III & I & 120 & 170 & 5 \\
\hline 11 & Female & 3 years +3 months & III & I & 140 & 180 & 11 \\
\hline 12 & Female & 10 years & IV & I & 80 & 140 & 5 \\
\hline 13 & Female & 7 years & IV & II & 110 & 160 & 4 \\
\hline
\end{tabular}



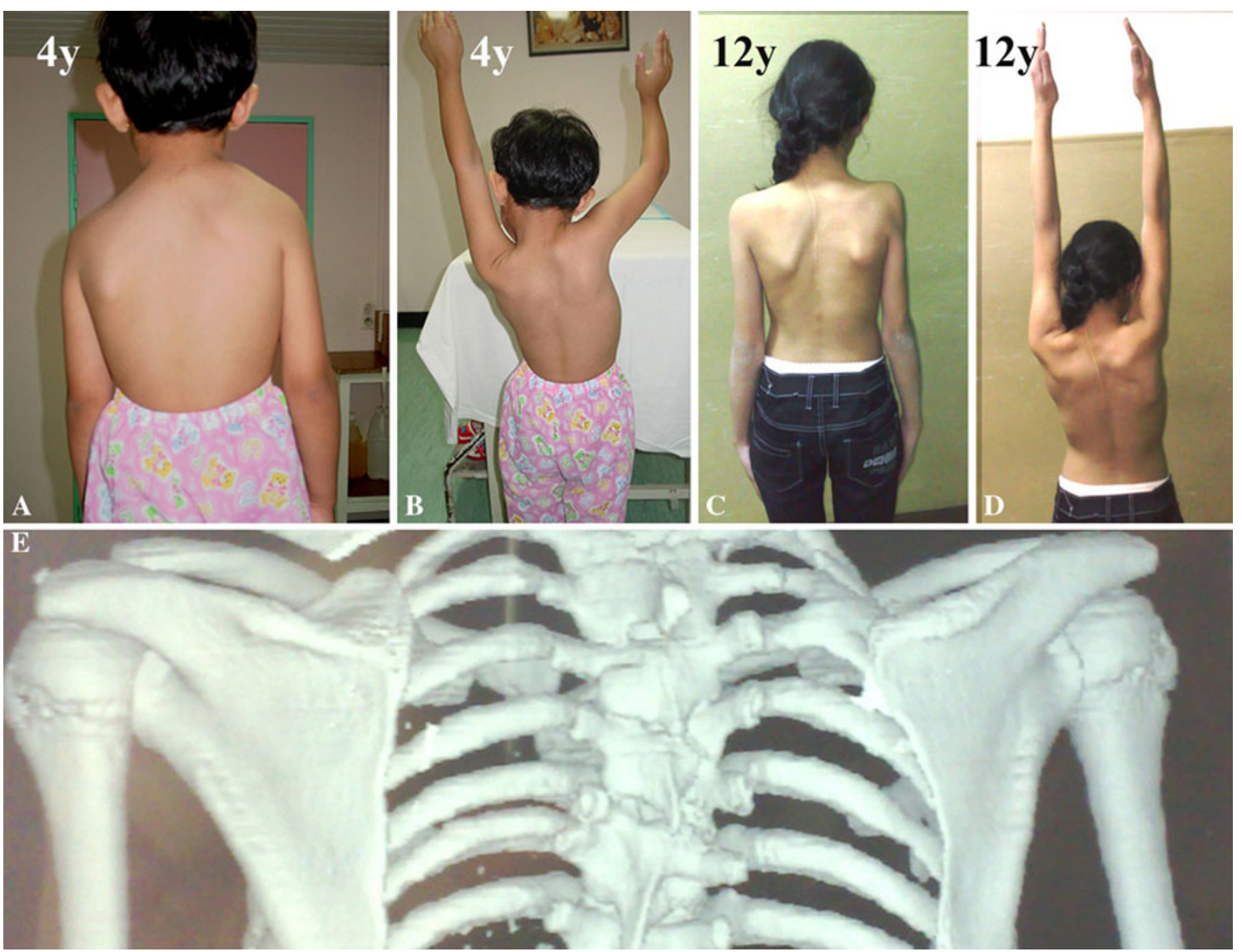

Fig. 2 A 4-year-and-5-month-old female child presented with deformity in the right scapula. a Photograph of the patient from behind while standing erect, showing prominent high scapula on the right side, causing elevation of the shoulder level at the same side. b Photograph of the patient from behind while standing erect and abducting both upper limbs, showing marked restriction of the abduction and compensating by lumbar lordosis to achieve proper abduction. c Photograph of the patient from behind while standing erect at the age of 12 years, showing both scapulae at the same level and well-balanced shoulder levels. d Photograph of the patient from behind while standing erect and abducting both upper limbs at the age of 12 years, showing $180^{\circ}$ abduction of both shoulders. e 3D computerized axial tomography scan (CAT Scan) of the both scapulae (posterior view) taken at the age of 12 years, showing upper thoracic scoliosis and well-balanced both scapulae with signs of the resected superiomedial portion of the scapula on the right side (Case no. 9 Table 2)
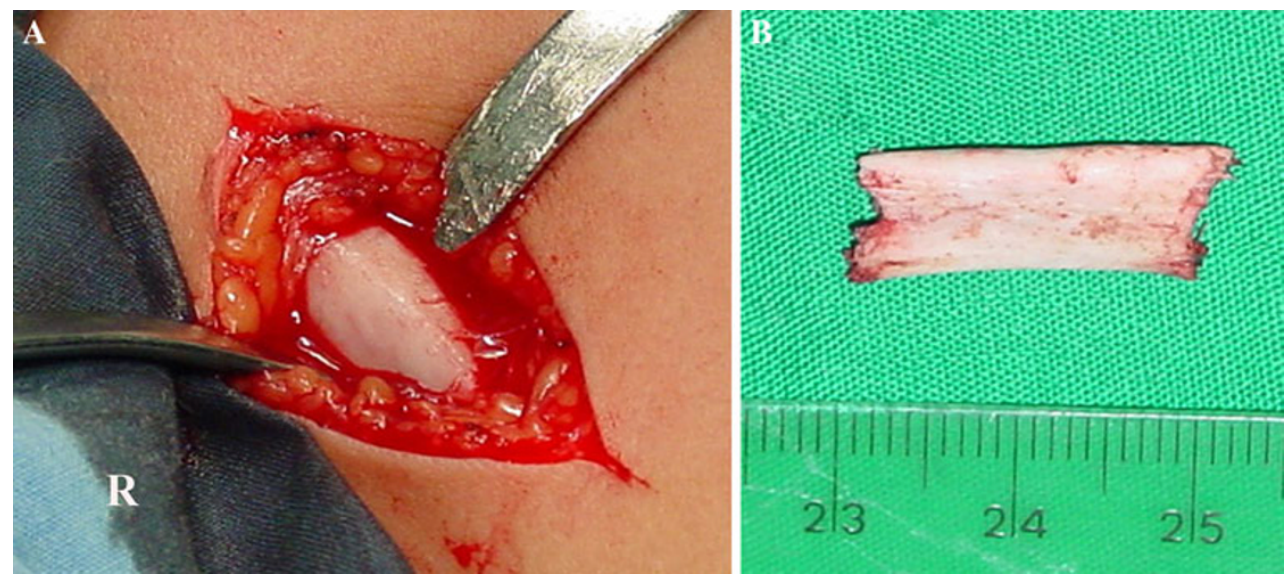

Fig. 3 a This is an intraoperative photograph for a 6-year-old male child, demonstrating the subperiosteal resection method, showing the exposed middle part of the right clavicle with small bone levers for protection the underlying neurovascular structures. b Intraoperative photograph of the resected segment of the right clavicle (Case no. 5 Table 2) 

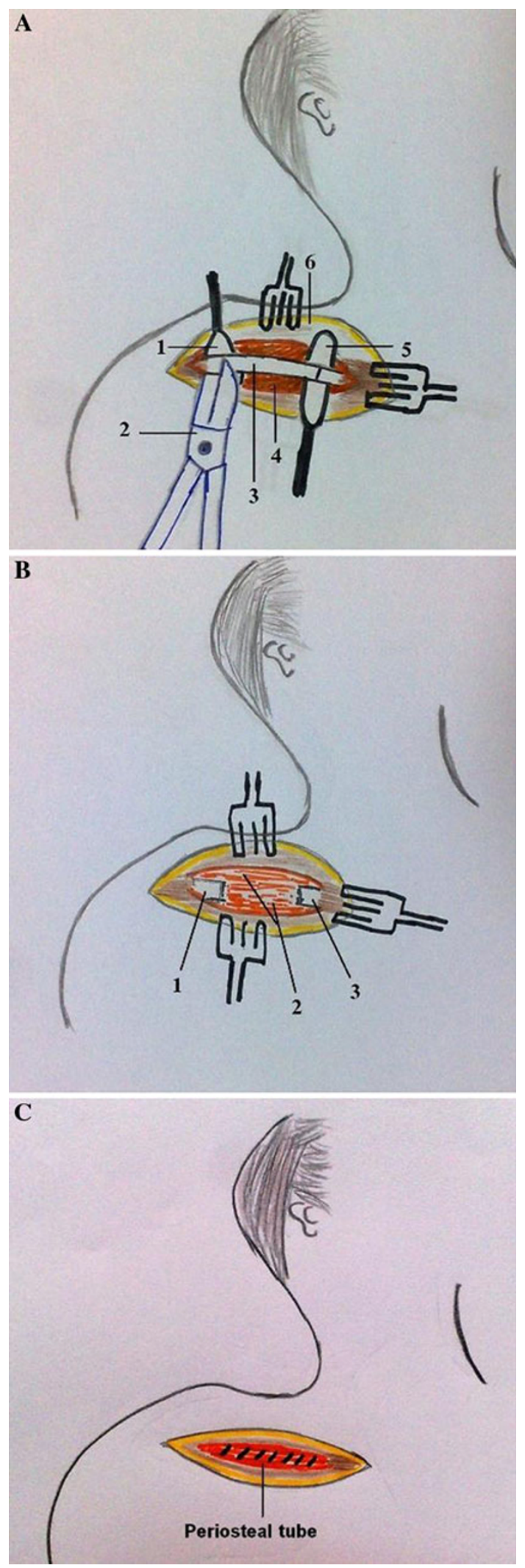

under the subcutaneous tissue at the region of the scapula. The wound was then closed in layers. Postoperative treatment consisted of application of a broad arm sling for
Fig. 4 Schematic drawing of the subperiosteal resection of the clavicle. a 1 Bone lever on the lateral side, 2 Bone cutter, 3 Middle of the clavicle, 4 Dissected periosteal sheath, 5 Bone lever on the medial side, 6 Retracted skin and subcutaneous tissue. $\mathbf{b}$ After removal of the middle segment of the clavicle subperiosteally. 1 Lateral part of the clavicle, 2 Intact periosteal sheath, 3 Medial part of the clavicle. c Closure of the periosteal sheath by continuous $4 / 0$ vicryl suture forming a periosteal tube

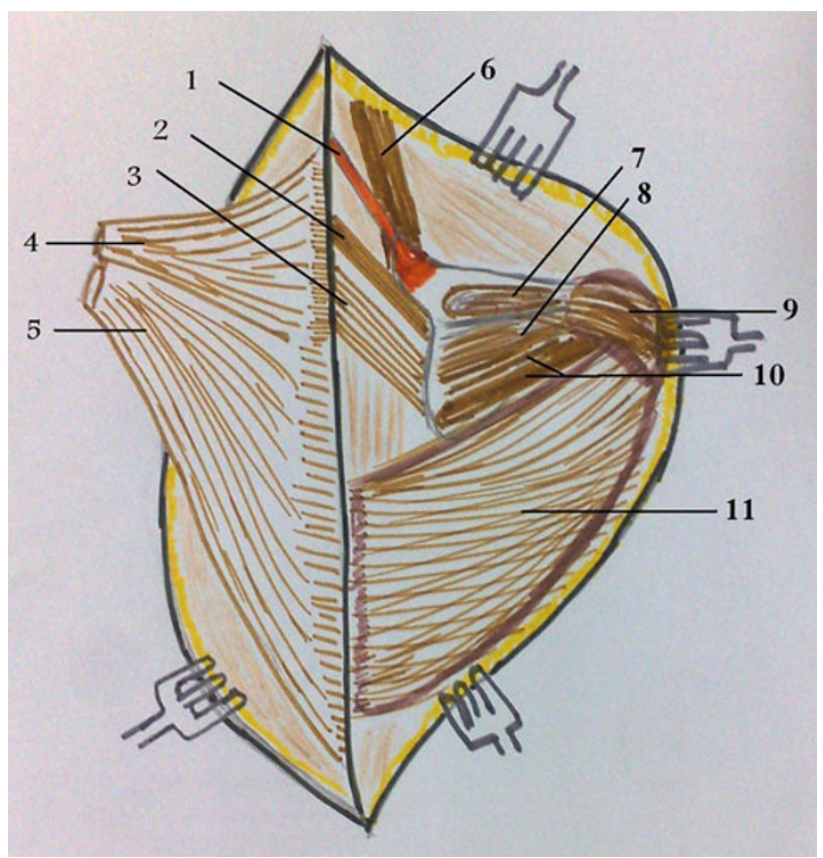

Fig. 5 Schematic drawing of the anatomical and pathological structures seen after reflection of the Trapezius muscle. 1 Omovertebral bar, 2 Rhomboides minor muscle, 3 Rhomboides major muscle, 4 Upper trapezius muscle, 5 Lower trapezius muscle, 6 Levator scapula muscle, 7 Supraspinatus muscle, 8 Infraspinatus muscle, 9 Deltoid muscle fibres, 10 Teres minor and major muscles, 11 Lattismus dorsi muscle

4 weeks, followed by a range of movement exercise to the shoulder girdle for 4 weeks. Cases of bilateral deformity were operated on 6 months after the operation on the other scapula.

\section{Results}

The results of the thirteen patients are shown in Table 3 . All the patients improved functionally and cosmetically after an average follow-up of 5.9 years (range 4-11 years). Preoperatively, the arc of total abduction (glenohumeral and scapulothoracic) ranged from 80 to $140^{\circ}$, and the average was $110^{\circ}$. The shoulders were level, and the range of motion was dramatically improved with an average range of abduction of $166.5^{\circ}$ (range $140-180^{\circ}$ ). Preoperatively, $38.46 \%$ of the patients had minimally affected 


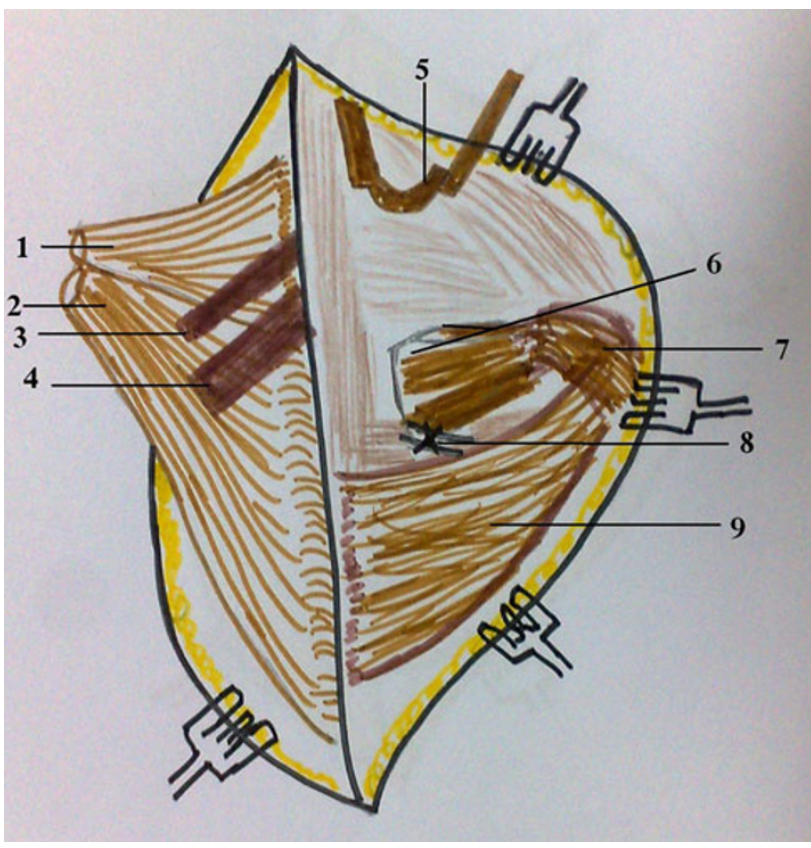

Fig. 6 Schematic drawing of the structures seen after resection of the Omovertebral bar and superior aspect of the supraspinus fossa, with fixation of the inferior scapular pole to the desired rib. 1 Upper trapezius muscle, 2 Lower trapezius muscle, 3 Detached Rhomboides minor muscle, 4 Detached Rhomboides major muscle, 5 Levator scapula muscle after lengthening, 6 Remaining part of the superior angle and superior border of the scapula, 7 Deltoid muscle fibres, 8 Anchoring vicryle suture of the inferior pole of the scapula to the desired rib, 9 Lattismus dorsi muscle

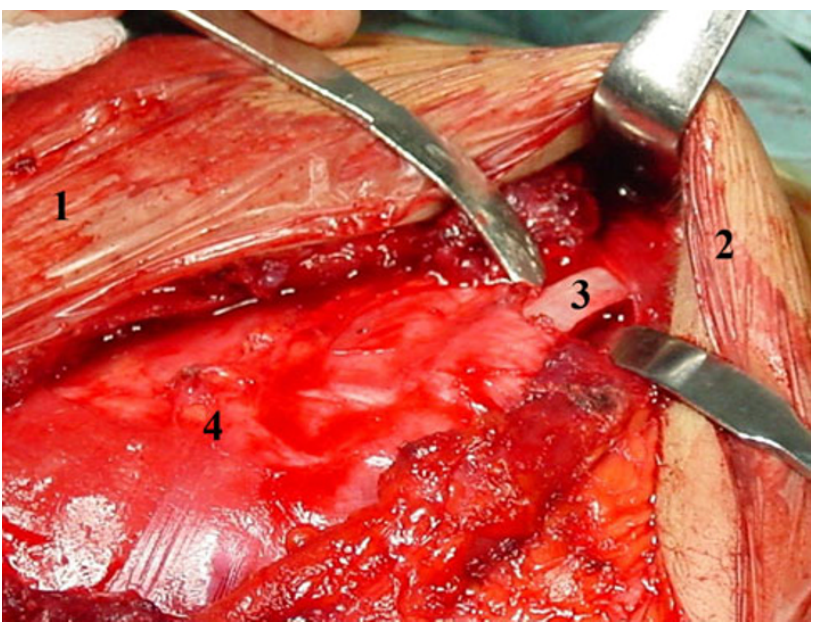

Fig. 7 Intraoperative photograph showing the status of the subperiosteal dissection of the rib posteriorly. 1 Cranial side, 2 Caudal side, 3 The exposed desired rib, 4 Posterior chest wall

abduction $\left(>120^{\circ}\right)$ (Cavendish grade III), and the operation was performed only for cosmetic improvement.

In an attempt to provide a quantitative approach in the evaluation of cosmetic improvement, the grading system of Cavendish was used. There was improved cosmesis with a

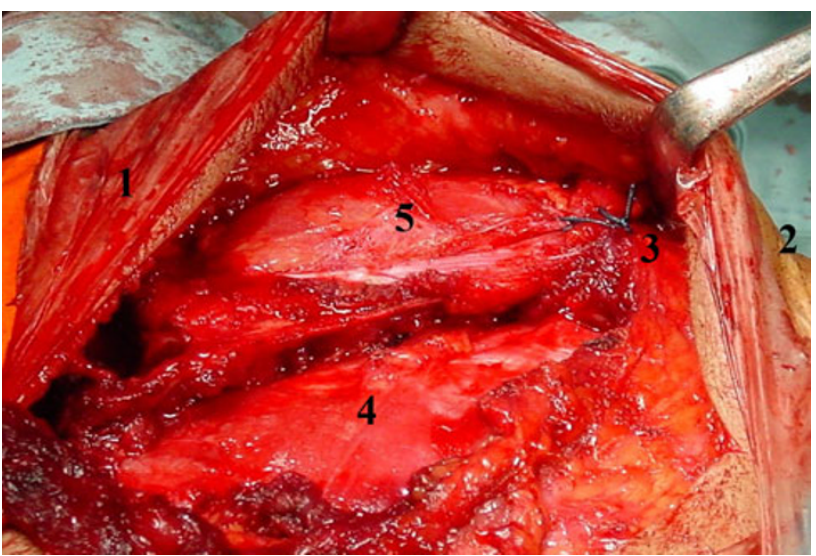

Fig. 8 Intraoperative photograph showing the status of the scapula in its descended site fixed to the rib. 1 Cranial side, 2 Caudal side, 3 The fixed inferior pole of the scapula to the desired rib, 4 Posterior chest wall, 5 The scapula in the new position

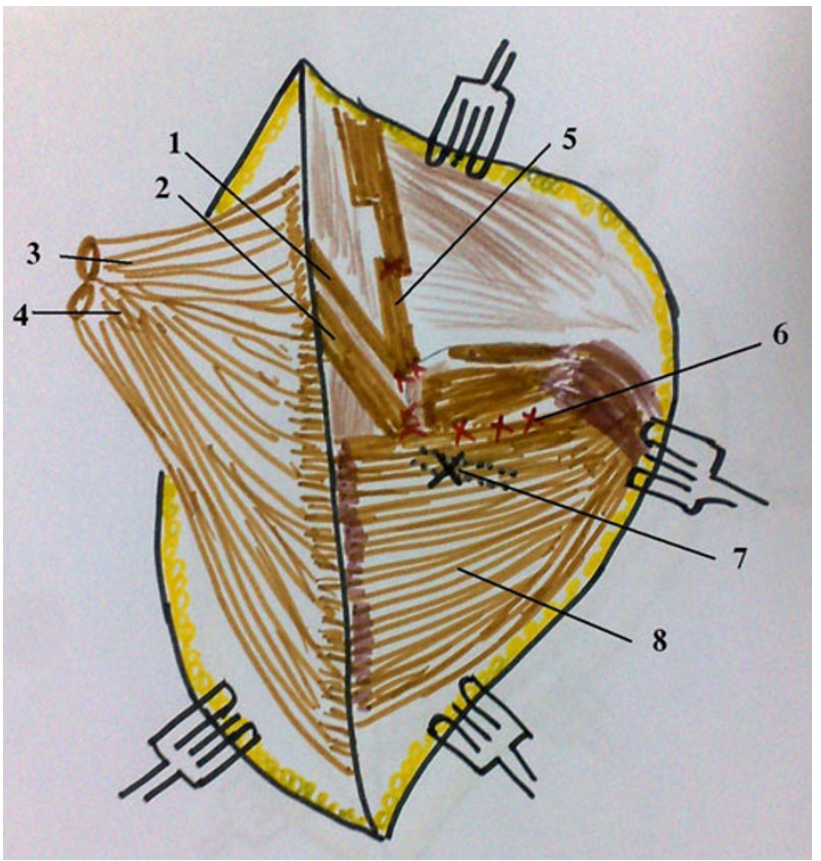

Fig. 9 Schematic drawing of the final status of the scapula in the new position. 1 Sutured Rhomboides minor muscle to proximal new insertion in the scapula, 2 Sutured Rhomboides major muscle to proximal new insertion in the scapula, 3 Upper trapezius muscle, 4 Lower trapezius muscle, 5 Sutured lengthened Levator scapula muscle to the remaining superior angle, 6 Sutured Lattismus dorsi muscle to the posterior scapular muscle, 7 The site of the anchored inferior pole to the rib is covered by the Lattismus dorsi muscle, 8 Lattismus dorsi muscle

decrease of at least 2 Cavendish Grade in all patients. Ten of the thirteen patients examined at follow-up were rated as grade I, and three patients were rated as grade II.

The average scapular lowering obtained was $3.7 \mathrm{~cm}$ (range 3-6.3 cm) compared with the preoperative level. As the Sprengel's deformity is a complex shoulder girdle 


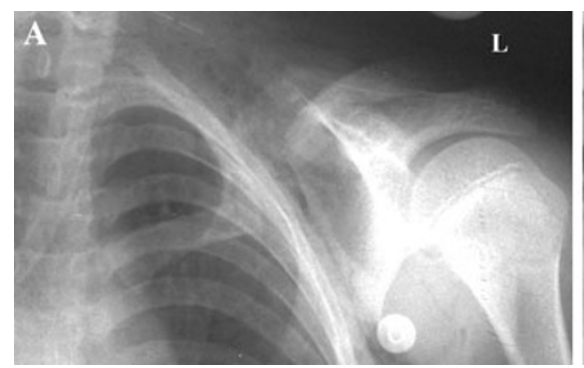

Fig. 10 a Plain radiograph (Anterior posterior view) of the left shoulder and clavicle in the first postoperative day, for 4-year-and-8month-old male child showing the bone defect in the clavicle after subperiosteal resection. b Plain radiograph (Anterior posterior view)

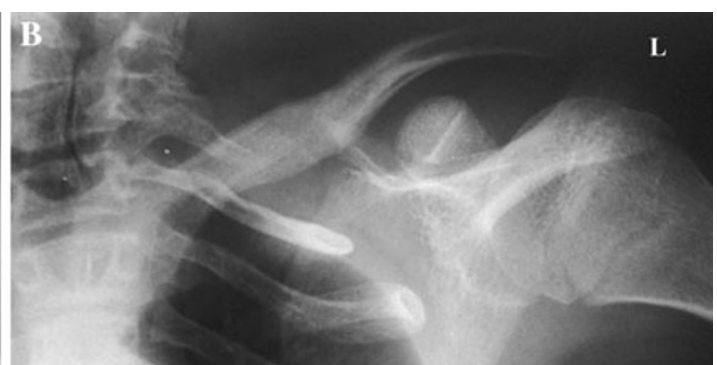

of the left shoulder and clavicle of the same child after five weeks of subperiosteal resection, showing complete regeneration of the defect and healing in the clavicle (Case no. 6 Table 2)

angulation, but the functional disabilities are often minimal [7]. Prenatal ultrasonographic diagnosis of Sprengel's deformity has been reported [14].

Sprengel's deformity is usually diagnosed at birth only in severe cases, and the diagnosis is more likely in patients with other associated congenital anomalies. In cases of mild and moderate deformity, diagnosis may be made at any age. As we are a tertiary referral centre, all patients were referred to us at the age of operation. Sprengel's deformity may be associated with congenital abnormalities of the other organ systems or may be part of syndromatic child $[4,15-20]$. One or more abnormalities are found in almost all patients $[11,21]$. The most common anomalies are congenital scoliosis, diastematomyelia, Klippel-Feil deformity, and absent or fused ribs [7].

In our study, twelve patients $(92.3 \%)$ had associated congenital anomalies. Seven of these twelve patients had more than one associated abnormality. The only syndrome that was found in our cases was Klippel-Feil syndrome $(15.38 \%)$. None of the described syndromes in the literature could be found in our cases. A frequent anomaly associated with Sprengel's deformity is the omovertebral connection, which could be fibrous band, cartilage, bone connection, or a combination of these. It connects the superomedial border of the scapula to the spinous process, lamina, or transverse processes of the cervical spine. It has been reported to be present in $18-60 \%$ of patients with congenital elevation of the scapula $[6,12,21]$. In our group of patients, it occurred in $46.15 \% \%$ of the patients, had significant limitation in abduction of the involved shoulder, and excision of omovertebral bone improved the abduction in all cases. Surgery for Sprengel's deformity can produce less lowering of the scapula than desired and occasionally can result in an injury to the brachial plexus or brachial artery [13].

Many surgical procedures have been designed to correct this deformity, but because of the abnormal scapula and the frequently associated anomalies of spine and chest-wall asymmetry, no single procedure can be expected to 
produce a perfect appearance in these children $[2,4,5,9-$ 11, 20, 22-27]. The operation performed in our patients differs from the original procedure described by Woodward or modified Green scapuloplasty $[6,7,10]$. We included the subperiosteal resection of the middle third of the clavicle as a routine procedure before correction of the deformity. This allows an easy downward movement of the scapula without neurovascular compromise.

Excision of the superomedial portion and the supraspinous part of the scapula improves the cosmetic appearance and decreased horizontal width helps to diminish the winging of the scapula. Some authors recommend clavicular osteotomy or morcellisation of the clavicle as a routine part of the procedure to diminish the risk of neurovascular compression that may occur between the clavicle and deformed chest wall $[5,8,27]$. These complications are particularly high in older children [7, 12]. On the other hand, some surgeons do not advise routine performance of clavicle surgery in all patients [7, 20].

In our series, however, we used routine clavicle surgery in the form of subperiosteal resection of one inch from the middle third clavicle to overcome these problems. The age at which surgical intervention should be undertaken has been discussed by various authors $[5,12,21]$.

In patients younger than three, the surgery is technically more difficult and children older than six are not suitable candidates for a scapular displacement procedure [12, 21]. None of our patients were younger than 3 years; on the other hand, six of our patients $(46.14 \%)$ were older than six. The recommended age at which surgery should be performed is between three and 8 years $[11,20]$. In our study, it was difficult to specify criteria to define the optimal age for operative correction.

The age of our patients at the time of the procedure varied from 3.3 to 10 years (average, 6 years 1 month). We did not find significant differences in any of the indices evaluated for our patients in different age groups at the time of surgery. We saw an average improvement of $56.5^{\circ}$ in combined shoulder abduction in our patients, which agrees with the average improvement of $23-77^{\circ}$ reported in the literature $[2,9,11,20,25,26]$. Cosmesis and functional impairment are the usual indications for surgical correction of the scapula [12]. All our patients had cosmesis problems, functional disability or both. Simple excision of the superomedial part of the scapula and the omovertebral bone or proximal muscles release to allow the scapula to be transplanted distally is associated with an unacceptable rate of incomplete correction or recurrent deformity [8, 12].

No recurrence of the deformity, however, has been noted following the Woodward procedure or modified green scapuloplasty $[6,10,11,20,26]$. Idiopathic postoperative scapular winging is a known cosmetic problem after the Woodward procedure $[2,8,11]$. We did not observe any case of postoperative winging in our patients. An unsightly postoperative surgical scar has been reported in various described procedures for correction of the deformity [9-11].

There were only minor complications noted, including one widened scar, one superior angle exostosis and one seroma. Temporary or permanent brachial plexus palsy has been described after surgical correction of Sprengel's deformity $[24,26]$. There were no cases of brachial plexus palsy induced by our method of surgery. Sprengel's deformity is a significant structural abnormality that produces an unsightly cosmetic appearance, restricts shoulder motion, and cannot be treated conservatively. We believe the most favourable cosmetic and functional results with low morbidity in patients with Sprengel's deformity are obtained by subperiosteal resection of the middle third of the clavicle combined with resection of the prominent superomedial border of the scapula, supraspinous portion as well as the omovertebral connection, and downward displacement of the scapula to a more inferior position.

Open Access This article is distributed under the terms of the Creative Commons Attribution License which permits any use, distribution and reproduction in any medium, provided the original author(s) and source are credited.

\section{References}

1. Van Heest AE (1996) Congenital disorders of hand and upper extremity. Pediatr Clin North Am 43:1113-1133

2. Leibovic SJ, Ehrlich MG, Zaleske DJ (1990) Sprengel deformity. J Bone Joint Surg [A] 72:192-197

3. Banniza Von Bazan U (1979) The association between congenital elevations of the scapula and diastematomyelia. J Bone Joint Surg [Br] 61:59-63

4. Khairouni A, Bensahel H, Csukonyi Z, Desgrippes Y, Pennecot GF (2002) Congenital high scapula. J Pediatr Orthop [Br] 11:85-88

5. Klisic P, Filipovic M, Uzelac O, Milinkovic Z (1981) Relocation of congenitally elevated scapula. J Pediatr Orthop 1:43-45

6. Woodward JW (1961) Congenital elevation of the scapula. J Bone Joint Surg [A] 43:219-228

7. Borges JLP, Shah A, Torres BC, Bowen JR (1996) Modified Woodward procedure for Sprengel deformity of the shoulder: long term results. J Pediatr Orthop 16:508-513

8. Ross DM, Cruess RC (1977) The surgical correction of congenital elevation of the scapula. A review of 77 cases. Clin Orthop 125:17-23

9. Mears DC (2001) Partial resection of the scapula and a release of the long head of triceps for the management of Sprengel's deformity. J Pediatr Orthop 21:242-245

10. Aydinli U, Ozturk C, Akesen B, Ozer O (2005) Surgical treatment of sprengel's deformity: a modified Green procedure. Acta Orthop Belg 71:264-268

11. Carson WG, Lovell WW, Whitesides TE (1981) Congenital elevation of the scapula. Surgical correction by the Woodward procedure. J Bone Joint Surg [Am] 63:1199-1207

12. Cavendish ME (1972) Congenital elevation of the scapula. J Bone Joint Surg [B] 54:395-408 
13. Pinsky HA, Pizzutillo PD, MacEwen GD (1980) Congenital elevation of the scapula. Orthop Trans 4:288-289

14. Chinn DH (2001) Prenatal ultrasonographic diagnosis of Sprengel's deformity. J Ultrasound Med 20:693-697

15. Waaler PE, Aarskog D (1980) Syndrome of hydrocephalus, costovertebral dysplasia and Sprengel anomaly with autosomal dominant inheritance. Neuropediatrics 11:291-297

16. Greenspan A, Cohen J, Szabo RM (1991) Klippel-Feil syndrome. An unusual association with Sprengel deformity, omovertebral bone, and other skeletal, hematologic and respiratory disorders. A case report. Bull Hosp Joint Dis Orthop Inst 51:54-62

17. Monier A, Van Maldergem L, Stevens R (2000) Association of cleft palate with Sprengel anomaly: confirmation of the HodgsonChiu syndrome. Am J Med Genet 95:401-403

18. Larson AR, Josephson KD, Pauli RM, Opitz JM, Williams MS (2001) Klippel- Feil anomaly with Sprengel anomaly, omovertebral bone, thumb abnormalities, and flexion-crease changes: novel association or syndrome? Am J Med Genet 101:158-162

19. Kaissi AA, Chehida FB, Gharbi H, Ghachem MB, Hendaoui L, Hennekam RC (2005) Familial vertebral segmentation defects, Sprengel anomaly, and omovertebral bone with variable expressivity. Am J Med Genet A 138:374-378
20. Grogan DP, Stanley EA, Bobechko WT (1983) The congenital undescended scapula, surgical correction by Woodward procedure. J Bone Joint Surg [Br] 65:598-605

21. Jeannopoulos CL (1961) Observations on congenital elevation of the scapula. Clin Orthop 20:132-137

22. McMurtry I, Bennet GC, Bradish C (2005) Osteotomy for congenital elevation of the scapula (Sprengel's deformity). J Bone Joint Surg [Br] 87:986-989

23. Farsetti P, Weinstein SL, Caterini R, De Maio F, Ippolito E (2003) Sprengel's deformity: long-term follow-up study of 22 cases. J Pediatr Orthop [B] 12:202-210

24. Wilkinson JA, Campbell D (1980) Scapular osteotomy for Sprengel's shoulder. J Bone Joint Surg [Br] 62:486-490

25. Zhang ZM, Zhang J, Lu ML, Cao GL, Dai LY (2007) Partial scapulectomy for congenital elevation of the scapula. Clin Orthop Relat Res 457:171-175

26. Bellemans M, Lamoureux J (1999) Results of surgical treatment of Sprengel deformity by a modified Green's procedure. J Pediatr Orthop [B] 8:194-196

27. Greitemann B, Rondhuis JJ, Karbowski A (1993) Treatment of congenital elevation of the scapula. $10(2-18)$ year follow-up of 37 cases of Sprengel's deformity. Acta Orthop Scand 64:365-368 